\title{
NIH STROKE SCALE CHANGES FOLLOWING CAROTID ARTERY STENTING
}

\author{
By
Hossam El-Din Hassan Hussien Hassan, Magdy Assad El-Hawary, Mohammed Sayed Ismail El-Shandawelly

Neurosurgery and Endovascular Neurosurgery Department, Faculty of Medicine, Al-Azhar University

Corresponding author: Hossam El-Din Hassan Hussien Hassan,

E-mail: $\underline{\text { Hossamhass2015@gmail.com }}$

\begin{abstract}
Background: Traditionally, carotid endarterectomy (CEA) has been the primary method of treating highgrade asymptomatic and symptomatic carotid artery stenosis. A carotid endarterectomy involves exposure of the carotid artery and removal of plaque, most typically from the carotid bulb and the proximal internal carotid artery, via a neck incision. However, in vascular surgery, as in many other surgical specialties, minimally invasive techniques have evolved over the years. These techniques offer the advantages of smaller incisions, reduced postoperative pain, reduced potential for postoperative wound complications, and a shorter length of stay in the hospital.
\end{abstract}

Objective: To assess the outcome of carotid stenting for carotid stenosis by assessing the changes in NIH stroke scale before and after carotid artery stenting.

Patients and Methods: This clinical trial study was conducted on 15 patients who underwent 15 carotid artery stenting (CAS). The study was carried at Al-Azhar University Hospitals and Mabart Masr Elkadema hospital in the period between July 2019 and July 2020. All patients with carotid stenosis with high-grade asymptomatic (more than $70 \%$ ) or symptomatic carotid artery stenosis treated with carotid artery stenting were included in this study, All patients with carotid stenosis treated with carotid artery end arterectomy, patients with unfavorable aortic arch anatomy including heavily calcified aortic arch or a type 3 aortic arch, and Patients with a common carotid artery length of less than $5 \mathrm{~cm}$ from the clavicle were excluded from our study. Cases were subjected to National Institute of Health Stroke Scale (NIHSS) before and after carotid artery stenting.

Results: Most of the current study participants were males (66.7\%) with a mean age of $58.9 \pm 8.9$ years, $80 \%$ were symptomatic and $20 \%$ were asymptomatic. Most of patients in our study had hypertension (HTN) (80\%), (53.3\%) had diabetes mellitus (DM) and ischemic heart disease (IHD) and (46.7\%) were smokers as males were higher than females. Also, $73.3 \%$ had dyslipidemia, $20 \%$ of patients were asymptomatic and $80 \%$ were symptomatic. Motor weakness was common especially on the left side (47.7\%) of patients and right side (20\%). Also, dysarthria was presented among $20 \%$ of patients, while transient ischemic attack (TIA) was presented among $13.3 \%$ of patients. Syncopal attack and deterioration of consciousness were among $6.7 \%$ of patients. In our study the degree of stenosis by diagnostic Cathter angiography (DCA) ranged from $60 \%$ to $90 \%$ with a mean of $72.67 \% \pm 9.2$. Right side was more affected $(60 \%)$ than left side $(40 \%)$. As regard National Institute of Health Stroke Scale (NIHSS) constructs, our patients had statistically significant improvement in level of consciousness, level of consciousness (loc) questions, loc commands, sensation and extinction/inattention occurred after 3 months. Also, our patients showed statistical significant improvement in best gaze, motor drift, best language and dysarthria after 3 months. Motor power of left arm and left leg showed statistically insignificant mild deterioration immediately after stenting. Visual field, facial palsy and limb ataxia constructs showed insignificant differences among our study patients as no improvement occurred. 
Conclusion: CAS showed a high technical success rate and a good short term clinical outcome. CAS is a safe and efficacious procedure especially with the availability of proper materials and experienced staff.

Keywords: NIH Stroke Scale, Carotid Artery Stenting.

\section{INTRODUCTION}

Atherosclerotic disease at the bifurcation of the common carotid artery is associated with $20 \%$ to $30 \%$ of strokes. Given these public health concerns, research in the latter half of the 20th century focused on the optimal treatment of carotid stenosis and the clinical considerations and techniques related to performing carotid stenting have evolved. Although the efficacy of carotid stenting in certain situations is still debated, this procedure has been deemed beneficial for many groups of patients (Planton et al., 2017).

Carotid artery stenosis (CS) is one of the most significant risk factors for ischemic stroke. Chronic cortical hypoperfusion arising from $\mathrm{CS}$ is currently being investigated as an important source of cognitive impairments, regardless of whether it accompanies stroke. The artery-to-artery embolism caused by CS can result in multiple infarcts, leading to vascular cognitive impairments and vascular dementia (Byeol et al., 2015).

Carotid artery stenting (CAS) is a reasonable alternative to surgical carotid endarterectomy (CEA) in select patients with high-grade asymptomatic (more than $70 \%$ ) or symptomatic carotid artery stenosis. Indications for CAS include high surgical patient risk, such as severe pulmonary disease, recent myocardial infarction, unstable angina, or severe congestive heart failure; a history of prior neck radiation that is anticipated to make open surgical dissection difficult; a history of damage to contralateral vocal cords; the presence of a tracheostomy, contralateral carotid occlusion; and previous CEA with recurrent stenosis (Juniery et al., 2018).

The main contraindication to CAS via a transfemoral approach is unfavorable aortic arch anatomy. This can include a heavily calcified aortic arch or a type 3 aortic arch. A relative contraindication can be a history of severe allergic reaction to intravenous contrast dye. However, patients can be pre-medicated to mitigate some of this risk. For a transcarotid approach, a common carotid artery length of less than $5 \mathrm{~cm}$ from the clavicle is considered inadequate (Koge et al., 2018).

There are different types of carotid stents. The different geometries and working principles of carotid stents (nitinol or cobalt chromium, open- or closed-cell configuration) provide each product with unique functional properties. The individual characteristics of each device may make it an attractive choice in one circumstance but render it less desirable in other situations. In approximately $75 \%$ of all procedures, all types of stents will achieve similar outcomes, making adequate device selection unnecessary. For the remaining quarter, careful preoperative screening is mandatory (Doig et al., 2016).

The National Institutes of Health Stroke Scale (NIHSS) can be used as a clinical stroke assessment tool to evaluate and document neurological status in stroke patients. The stroke scale is valid 
for predicting lesion size and can serve as a measure of stroke severity. The NIHSS has been shown to be a predictor of both short and long term outcome of stroke patients. The scale is made up of 11 different elements that evaluate specific ability. The score for each ability is a number between 0 and 4,0 being normal functioning and 4 being completely impaired. The patient's NIHSS score is calculated by adding the number for each element of the scale; 42 are the highest score possible. In the NIHSS, the higher the score, the more impaired a stroke patient is (Chen et al., 2017).

The present work aimed to review the outcome of carotid stenting for carotid stenosis by studying the changes in NIH stoke scale before and after carotid artery stenting.

\section{PATIENTS AND METHODS}

This was a prospective comparative study conducted on 15 patients with highgrade asymptomatic or symptomatic carotid stenosis who were scheduled to undergo carotid artery stenting. The patients were recruited from Neurosurgery Department, Al-Azhar University Hospitals and Mabrat Masr Elkadema Hospital during the period from July 2019 till July 2020.

The study ran in concordance with international ethical standards and applicable local regulatory guidelines. A written informed consent was obtained from every eligible patient. Patients were informed about the study objectives, methodology, risk, and benefit. The study's protocol was reviewed and approved by institutional Review Board (IRB), ethics committee or audit department of Faculty of Medicine, AlAzhar University.

Patients underwent: Full history, clinical examination, magnetic resonance imaging (MRI), magnetic cerebral angiography, carotid duplex, NIH stroke scale, three months clinical outcomes of the included patients and procedure-related complications.

The NIH Stroke Scale (NIHSS) is a tool used by healthcare providers to objectively quantify the impairment caused by a stroke. The NIHSS is composed of 11 items, each of which scores a specific ability between a 0 and 4 . For each item, a score of 0 typically indicates normal function in that specific ability, while a higher score is indicative of some level of impairment. The individual scores from each item are summed in order to calculate a patient's total NIHSS score. The maximum possible score is 42 , with the minimum score being a 0 .

The primary outcome in the present study was the changes in the NIH Stroke Scale immediately and three months after the carotid stenting. The secondary outcome was the correlation between the change in NIH Stroke Scale and the clinical outcomes of the included patients.

\section{Statistical Analysis:}

An Excel spreadsheet was established for the entry of data. We used validation checks on numerical variables and optionbased data entry method for categorical variables to reduce potential errors. The analyses were carried with SPSS software (Statistical Package for the Social Sciences, version 24, SSPS Inc, Chicago, IL, USA). A p-value $<0.05$ was 
considered statistically significant. The comparison between groups regarding qualitative data was done by using Chisquare test. The comparison between more than two paired groups regarding quantitative data and parametric distribution was done by using Repeated
Measures ANOVA test followed by Post hoc analysis using Bonfirroni test. The confidence interval was set to $95 \%$ and the margin of error accepted was set to $5 \%$. So, the p-value was considered significant at the level of $\leq 0.05$.

\section{RESULTS}

Most of the current study participants were males $(66.7 \%)$ with mean age of (58.9 \pm 8.9$)$ years. $80 \%$ were symptomatic and $20 \%$ were asymptomatic. Most of patients had HTN (80\%), (73.3\%) had dyslipidemia, (53.3\%) had DM and IHD and $(46.7 \%)$ were smokers. As there was $20 \%$ of patients were asymptomatic and $80 \%$ were symptomatic, motor weakness was common especially on the left side
(47.7\%) of patients and right side (20\%). Also, dysarthria was presented among $(20 \%)$ of patients, while TIA was presented among (13.3\%) of patients. Syncopal attack and deterioration of consciousness were among $(6.7 \%)$ of patients. The degree of stenosis by DCA ranged from $60 \%$ to $90 \%$ with a mean of $72.67 \% \pm 9.2$. Right side was more affected (60\%) than left side (40\%) (Table 1).

Table (1): Base-line characteristics of the population study

\begin{tabular}{|l|c|}
\hline Variables & $(\mathbf{n}=15)$ \\
\hline Age: & $(58.9 \pm 8.9)$ \\
\hline Mean \pm SD & $(39-71)$ \\
\hline Range & $10(66.7 \%)$ \\
\hline Gender & $5(33.3 \%)$ \\
\hline Males (n, \%) \\
\hline Females (n, \%) \\
\hline Presentation \\
\hline Symptomatic & $12(80 \%)$ \\
\hline Asymptomatic & $3(20 \%)$ \\
\hline Comorbidities & $8(53.3 \%)$ \\
\hline Diabetes mellitus & $12(80 \%)$ \\
\hline Hypertension & $8(53.3 \%)$ \\
\hline Ischemic heart diseases & $11(73.3 \%)$ \\
\hline Dyslipidemia & $7(46.7 \%)$ \\
\hline Smoking & $2(13.3 \%)$ \\
\hline TIA & $1(6.7 \%)$ \\
\hline Syncopal attack & $1(6.7 \%)$ \\
\hline Deterioration of consciousness & $3(20 \%)$ \\
\hline Motor weakness & $7(46.7 \%)$ \\
\hline Rt side & $3(20 \%)$ \\
\hline Lt side & \\
\hline Dysarthria & $9(60 \%)$ \\
\hline Side of carotid stenosis & $6(40 \%)$ \\
\hline Right side & $(72.67 \pm 9.2)$ \\
\hline Left side & $3(20 \%)$ \\
\hline Degree of carotid stenosis (mean \pm SD) & $12(80 \%)$ \\
\hline Stenosis $<70 \%$ & \\
\hline Stenosis $\geq 70 \%$ & \\
\hline
\end{tabular}


NIHSS changes of all cases from baseline value to 3 months follow up and NIHSS constructs changes of all cases from baseline value to 3 months follow up. NIHSS score of $4.8 \pm 5.03$ before stenting, $5.07 \pm 4.98$ immediately after stenting and $3 \pm 2.7$ three months after stenting with statistical significant difference between NIHSS immediately after stenting and three months after stenting. The differences immediately after stenting indicate mild deterioration while after three months the difference indicates improvement in patient's status. 93.3\% of patients had no change in NIHSS score immediately after stenting and only one case was mildly deteriorated. $53.7 \%$ of patients had no change, $40 \%$ were improved and one case still showing mild deterioration (6.7\%) after three months after stenting. As regard NIHSS constructs, our patients had highly statistically significant improvement in level of consciousness, loc questions, loc commands, sensation and extinction/ inattention as p-value less than 0.001 as improvement occurred after 3 months. Also, our patients showed statistical significant improvement in best gaze, motor drift, best language and dysarthria $(\mathrm{p}=0.032, \quad 0.021, \quad 0.044$ and 0.026 , respectively) as improvement occurred after 3 months. Meanwhile motor power of left arm and left leg showed statistically insignificant mild deterioration immediately after stenting. While visual field, facial palsy and limb ataxia constructs showed insignificant differences among our study patients as no improvement occurred (Table 2). 
Table (2): NIHSS changes of all cases from baseline value to three month follow up

\begin{tabular}{|c|c|c|c|c|c|c|c|}
\hline \multirow[b]{2}{*}{ Parameters } & \multicolumn{3}{|c|}{ Changes } & \multirow[b]{2}{*}{ P-value } & \multirow[b]{2}{*}{ P1 } & \multirow[b]{2}{*}{$\mathbf{P 2}$} & \multirow[b]{2}{*}{ P3 } \\
\hline & $\begin{array}{l}\text { Before } \\
\text { stenting }\end{array}$ & $\begin{array}{l}\text { Immediately } \\
\text { after stenting }\end{array}$ & $\begin{array}{c}\text { 3 Months } \\
\text { after stenting }\end{array}$ & & & & \\
\hline NIHSS & $4.8 \pm 5.03$ & $5.07 \pm 4.98$ & $3.0 \pm 2.7$ & 0.033 & 0.799 & 0.037 & 0.016 \\
\hline $\begin{array}{l}\text { NIHSS } \\
\text { No deterioration } \\
\text { Mild deterioration } \\
\text { Moderate deterioration } \\
\text { Severe deterioration }\end{array}$ & $\begin{array}{c}5(33.3 \%) \\
4(26.7 \%) \\
5(33.3 \%) \\
1(6.7 \%)\end{array}$ & $\begin{array}{c}5(33.3 \%) \\
3(20.0 \%) \\
6(40.0 \%) \\
1(6.7 \%) \\
\end{array}$ & $\begin{array}{c}5(33.3 \%) \\
7(46.7 \%) \\
3(20.0 \%) \\
0(0.0 \%)\end{array}$ & 0.696 & - & - & - \\
\hline Level of consciousness & $2.8 \pm 0.08$ & $2.8 \pm 0.08$ & $0.6 \pm 0.19$ & $<0.001 * 1$ & 1.000 & $<0.001$ & $<0.001$ \\
\hline Loc questions & $1.67 \pm 0.10$ & $1.67 \pm 0.10$ & $0.42 \pm 0.21$ & $<0.001 * 1$ & 1.000 & $<0.001$ & $<0.001$ \\
\hline Loc commands & $1.52 \pm 0.19$ & $1.52 \pm 0.19$ & $0.39 \pm 0.13$ & $<0.001 * 1$ & 1.000 & $<0.001$ & $<0.001$ \\
\hline $\begin{array}{l}\text { Best gaze "Horizontal } \\
\text { eye movements" }\end{array}$ & $1.07 \pm 0.32$ & $1.07 \pm 0.32$ & $0.33 \pm 0.11$ & $0.032 * 1$ & 1.000 & $<0.001$ & $<0.001$ \\
\hline Visual field & $2.1 \pm 0.28$ & $2.1 \pm 0.28$ & $2.1 \pm 0.28$ & $1.00^{1}$ & - & - & - \\
\hline Facial palsy & $2.2 \pm 0.19$ & $2.2 \pm 0.19$ & $2.2 \pm 0.19$ & $1.00^{1}$ & - & - & - \\
\hline $\begin{array}{l}\text { Motor drift } \\
\text { Motor Lt arm }\end{array}$ & $3.61 \pm 0.11$ & $3.72 \pm 0.11$ & $2.01 \pm 0.09$ & $0042 * 1$ & $<0001$ & $<0001$ & $<0001$ \\
\hline Motor power Rt arm & $3.64 \pm 0.19$ & $3.64 \pm 0.19$ & $1.98 \pm 0.10$ & $0.034 * 1$ & 1.000 & $<0.001$ & $<0.001$ \\
\hline Motor power Lt leg & $3.68 \pm 0.22$ & $3.74 \pm 0.08$ & $1.87 \pm 0.21$ & $0.021 * 1$ & $<0.001$ & $<0.001$ & $<0.001$ \\
\hline Motor power Rt leg & $3.54 \pm 0.15$ & $3.54 \pm 0.15$ & $1.96 \pm 0.12$ & $0.030 * 1$ & 1.000 & $<0.001$ & $<0.001$ \\
\hline Limb Ataxia & $1.23 \pm 0.24$ & $1.23 \pm 0.24$ & $1.23 \pm 0.24$ & $1.00^{1}$ & - & - & - \\
\hline Sensation & $1.26 \pm 0.19$ & $1.26 \pm 0.19$ & $0.31 \pm 0.08$ & $<0.001 * 1$ & 1.000 & $<0.001$ & $<0.001$ \\
\hline Best Language & $2.2 \pm 0.26$ & $2.2 \pm 0.26$ & $1.7 \pm 0.31$ & $0.044 * 1$ & 1.000 & $<0.001$ & $<0.001$ \\
\hline Dysarthria & $1.21 \pm 0.22$ & $1.21 \pm 0.22$ & $0.77 \pm 0.28$ & $0.026 * 1$ & 1.000 & $<0.001$ & $<0.001$ \\
\hline Extinction/inattention & $1.03 \pm 0.31$ & $1.03 \pm 0.31$ & $0.30 \pm 0.11$ & $<0.001 * 1$ & 1.000 & $<0.001$ & $<0.001$ \\
\hline
\end{tabular}

Repeated Measures ANOVA test followed by post hoc analysis using Bonferoni test.

*Statistically significant as $\mathrm{p}<0.05$.

P1: Comparison between NIHSS before stenting and immediately after stenting

P2: Comparison between NIHSS before stenting and 3months after stenting

P3: Comparison between NIHSS immediately after stenting and 3months after stenting

- Mild deterioration $=(1-4$ scores change of the initial NIHSS $)$.

- Moderate deterioration $=(5-15$ scores change of the initial NIHSS $)$.

- Severe deterioration $=(>15$ scores change of the initial NIHSS $)$.

\section{DISCUSSION}

This clinical trial study was conducted on a (15) patients who underwent 15 CAS. Most of the current study participants were males $(66.7 \%)$ with mean age of $(58.9 \pm 8.9)$ years. $80 \%$ were symptomatic and $20 \%$ were asymptomatic. In agreement with a systematic review of Prevalence of asymptomatic carotid artery stenosis according to age and sex, prevalence of moderate stenosis increases with age in both men and women, but men at all ages have the higher prevalence estimates (Howard et al., 2011). Age and multiplicity of risk factors are thought to be the determinant of carotid artery disease. The mean age of the present study was younger than other previous studies (Baligh et al., 2013). The presence of patients with younger age in the current study may be explained by the difference in vascular risk factors between the current study and the other studies.

Most of patients in our study had HTN (80\%), 53.3\% had DM and IHD and $(46.7 \%)$ were smokers as males were 
higher than females. Also, 73.3\% had dyslipidemia, with a strong relationship between total cholesterol, low-density lipoprotein cholesterol, and the extent of extracranial carotid artery atherosclerosis and wall thickness.

Wen et al. (2018) study on patients with carotid stenosis, $65.48 \%$ had hypertension, $17.86 \%$ had diabetes mellitus, and $9.52 \%$ had coronary disease.

Reported populations with carotid artery stenosis of the included RCTs were relatively similar. Between $88.0 \%$ and $90.4 \%$ of enrolled patients had hypertension (Sardar et al., 2017). The proportion of smokers ranged between $23.2 \%$ and $90.6 \%$, and the proportion with diabetes mellitus varied from $14.1 \%$ to 34.8\% (Moresoli et al., 2017).

In our study, there was $20 \%$ of patients were asymptomatic and $80 \%$ were symptomatic, motor weakness was common especially on the left side $(47.7 \%)$ of patients and right side (20\%). Also, dysarthria was presented among $20 \%$ of patients, while TIA was presented among $13.3 \%$ of patients. Syncopal attack and deterioration of consciousness were among $6.7 \%$ of patients.

This was in agreement with Solomon and Grotta (2013) who reported that the plaque can be stable and asymptomatic, or it can be a source of embolization. Emboli break off from the plaque and travel through the circulation to blood vessels in the brain. As the vessels get smaller, an embolus can lodge in the vessel wall and restrict the blood flow to parts of the brain. This ischemia can either be temporary, yielding a transient ischemic attack, or permanent resulting in a thromboembolic stroke.
In our study, the degree of stenosis by DCA ranged from $60 \%$ to $90 \%$ with a mean of $72.67 \% \pm 9.2$. Right side was more affected (60\%) than left side (40\%). Similarly, in El Sudany et al. (2018) study, the degree of stenosis by DSA ranged from $55 \%$ to $97 \%$ with a mean of $82.58 \% \pm 11.27$. Twenty six cases $(52 \%)$ underwent right CAS and 24 cases (48\%) underwent left CAS.

Our results found that our patients had NIHSS score of $4.8 \pm 5.03$ before stenting, $5.07 \pm 4.98$ immediately after stenting, and $3 \pm 2.7$ three months after stenting with statistical significant difference between NIHSS immediately after stenting, and three months after stenting. The difference immediately after stenting indicating mild deterioration, while after three months the difference indicates improvement in patient's status.

In El Sudany et al. (2018) study, all cases were assessed using NIHSS as a base line before CAS, immediately after and at one month follow up visit. Changes in the NIHSS. Six cases (12\%) showed new lesions at brain DW-MRI. Among them, three cases (6\%) showed corresponding clinical deterioration and the other three were asymptomatic. The three cases that showed clinical deterioration were symptomatic and underwent left CAS.

In our study, $93.3 \%$ of patients had no change in NIHSS score immediately after stenting and only one case was mildly deteriorated. $53.7 \%$ of patients had no change, $40 \%$ improved and one case still showing mild deterioration (6.7\%) after three months after stenting. The cases with no change indicating that our intervention is safe and can be used as 
alternative to carotid endarterectomy. Also, our cases showed no deterioration during our follow-up period which denoting that CAS may be prophylactic against more strokes.

Study of Song et al. (2017) who retrospectively analyzed gerontal patients diagnosed with asymptomatic carotid artery stenosis (ACAS) showed that the difference of NIHSS score before and after treatment were greater than or equal to 11. It indicated that CEA was beneficial for the recovery of patients with nerves injury, whose NIHSS scores were greater than or equal to 11 . The score of NIHSS was mainly used to assess the cerebral stroke outcome caused by circulating blood supply disorders, using a score to refine the specific neurological function, the higher the score, the heavier the nerve damage (Radak et al., 2014).

There are studies showing that NIHSS score can reduce the research error, so it is widely used in cerebral apoplexy related research. The significance of treatment was small in two groups with NIHSS score $>20$ points. The reason might be the patient's neurological impairment was severe, brain nerve cells were irreversible necrosis, even treated by revascularization, and necrotic brain tissue was still unable to restore its normal function in a short term. Those patients were mostly doing rehabilitation exercise, but good circulation perfusion was not meaningless. It could create an environment to reproduce nerve cell and connect synapsis (Cremonesi et al., 2015).

Kanematsu et al. (2017) study patients who underwent CAS within 14 days of stroke and treated by urgent CAS. In all patients, the National Institutes of Health
Stroke Scale (NIHSS) score was recorded and the modified Rankin scale (mRS).

Our patients had statistically significant improvement in level of consciousness, loc questions, loc commands, sensation and extinction/inattention as p-value less than 0.001 as improvement occurred after 3 months. Also, our patients showed statistical significant improvement in best gaze, motor drift, best language and dysarthria as improvement occurred after 3 months. Meanwhile motor power of left arm and left leg showed statistically insignificant mild deterioration immediately after stenting. Visual field, facial palsy and limb ataxia constructs showed insignificant differences among our patients.

Imai et al. (2011) reported patients with ICA occlusion or high-grade stenosis underwent urgent CAS. Urgent CAS resulted in significant improvement in the NIHSS score, when compared before and after urgent CAS. Also, systematic review found that CAS was associated with decreased risks of periprocedural MI, hematoma, and cranial nerve palsy but with increased risks of periprocedural and long-term stroke (Moresoli et al., 2017).

Thus, in this small study, emergency carotid artery stent placement compared with historical control subjects treated with medical management was associated with a favorable outcome. More study is required to determine the role of this therapy in the treatment of patients with acute ischemic stroke and an associated significant ipsilateral carotid artery stenosis or occlusion.

Some study had reported efficacy of emergency CEA in carotid-related stroke 
(Brandl et al., 2011). A study by McPherson et al. (2010) of emergency CEA reported results comparable to those of the present emergency stent placement study.

\section{CONCLUSION}

CAS showed a high technical success rate and a good short term clinical outcome. CAS is a safe and efficacious procedure especially with the availability of proper materials and experienced staff. Further large multicenter RCTs for evaluation of this treatment strategy should be done.

\section{REFERENCES}

1. Baligh E, Abdallah F, Shamloul R, Shaker E and Shebly $H$ (2013): The impact of vascular risk factors multiplicity on severity of carotid atherosclerosis-A retrospective analysis of 1969 Egyptian subjects. World Journal of Cardiovascular Diseases, 3:414-418.

2. Brandl R, Brauer RB and Maurer PC (2011): Urgent carotid endarterectomy for stroke in evolution. Vasa., 30:115-121.

3. Byeol AY, Sang WS, Sang MC, Dae HK, Jae KC, SoJeong $Y$ and Kyung WP (2015): Effect of Carotid Artery Stenting on Cognitive Function in Patients with Carotid Artery Stenosis: A Prospective, 3-Month-Follow-Up Study. J Clin Neurol., 11(2): 149-156.

4. Chen Y, Song Y, Huang J, Qu M, Zhang Y, Geng J, Yang GY (2017): Increased circulating exosomal miRNA-223 is associated with acute ischemic stroke. Frontiers in Neurology, 8:57-61.

5. Cremonesi A, Castriota F, Secco GG, Macdonald S and Roffi M (2015): Carotid artery stenting: an update. Eur Heart J., 36: 1321.

6. Doig D, Turner EL, Dobson J, Featherstone RL, Lo RTH, Gaines PA and Brown MM (2016): Predictors of Stroke, Myocardial Infarction or Death within 30 Days of Carotid Artery Stenting: Results from the International Carotid Stenting Study. European Journal of
Vascular and Endovascular Surgery, 51(3): 327-334.

7. El Sudany AH, Zaki AA and Abdulghani MO (2018): Assessment of endovascular management of extracranial internal carotid artery stenosis. The Egyptian Journal of Hospital Medicine, 67(1): 392-396.

8. Howard VJ, Voeks JH and Lutsep HL (2011): Does sex matter? Thirty-day stroke and death rates after carotid artery stenting in women versus men: results from the Carotid Revascularization Endarterectomy versus Stenting Trial (CREST) lead-in phase. Stroke, 1140-1147.

9. Imai K, Mori T, Izumoto H, Watanabe M and Majima K (2011): Emergency carotid artery stent placement in patients with acute ischemic stroke. AJNR Am J Neuroradiol., 26: 1249-1258.

10. Juniery PM, Mathur A and Seth A (2018): TCTAP A-053 Outcome of Carotid Artery Stenting in Patient with Combined Carotid and Coronary Artery Disease: Journal of the American College of Cardiology, 71(16): 2930.

11. Kanematsu $Y$, Satomi $J$ and Kuwayama $K$ (2017): Treatment Outcome of Carotid Artery Stenting Underwent within 14 Days of Stroke Onset-Consideration of Safety and Efficacy of Urgent Carotid Artery Stenting for Neurologically Progressing Patients. Neurologia Medico-Chirurgica, 57(6): 278283.

12. Koge J, Iwata T, Hashimoto T, Mizuta S, Nakamura Y, Tanaka E, Kawajiri M, Matsumoto $S$ and Yamada T (2018): Carotid artery stenting with proximal embolic protection via the transbrachial approach: sheath less navigation of a 9-F balloon-guiding catheter. Neuroradiology, 60(10):1097-1101.

13. McPherson CM, Woo D and Cohen PL (2010): Early carotid endarterectomy for critical carotid artery stenosis after thrombolysis therapy in acute ischemic stroke in the middle cerebral artery. Stroke, 32:20752080.

14. Moresoli P, Habib B and Reynier P. (2017): Carotid stenting versus endarterectomy for 
asymptomatic carotid artery stenosis: a systematic review and meta-analysis. Stroke, 48(8): 2150-2157.

\section{Planton M, Raposo N, Danet L, Albucher JF} and Péran $P$ (2017): Impact of spontaneous intracerebral hemorrhage on cognitive functioning: An update. Revue Neurologique, 173(8): 481-489.

16. Radak D, Tanaskovic S, Sagic D, Antonic Z, Babic S, Popov $P$, Matic $P$ and Rancic $Z$ (2014): Carotid angioplasty and stenting is safe and effective for treatment of recurrent stenosis after eversion endarterectomy. J Vasc Surg., 60: 645-651.

17. Sardar P, Chatterjee S, Aronow HD, Kundu A, Ramchand $P$ and Mukherjee D (2017): Carotid artery stenting versus endarterectomy for stroke prevention: a meta-analysis of clinical trials. J Am Coll Cardiol., 69:22662275 .

18. Solomon CG and Grotta JC (2013): Carotid Stenosis. New England Journal of Medicine, 369(12): 1143-1150.

19.Song R, Sun X, Qu B and Wang $Z$ (2017): Comparative efficacy and safety of carotid endarterectomy and carotid angioplasty stenting in the treatment of asymptomaticcarotid artery stenosis. Int J Clin Exp Med., 10: 10773-10781.

20. Wen L, Wang S, Liu L, Chen L, Geng J, Kuang L, Qian G, Su J, Chen K and Zhou Z (2018): The Long-Term Efficacy and Safety of Carotid Artery Stenting among the Elderly: A Single-Center Study in China. Behavioural Neurology, 2018:4707104. 


\section{تغير ات مقياس المعهد القومي للصحة للسكتة الدماغية عقب تدعيم الثريان السباتي}

حسام الدين حسن حسين حسن، مجدي أسعد الهواري، محمد سيد إسماعيل الشندويلي قسم جراحة المخ والأعصاب، كلية الطب، جامعة الازهر

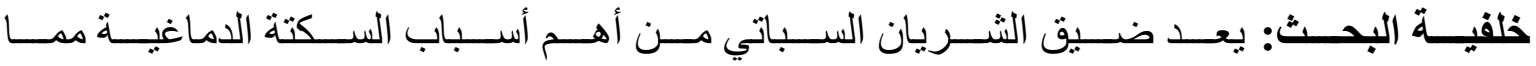

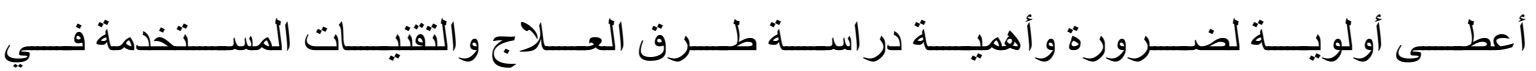

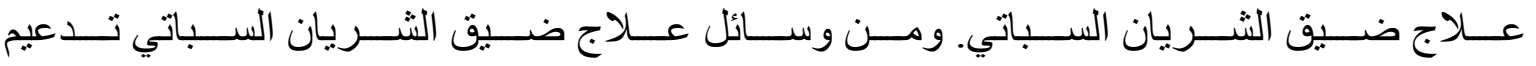

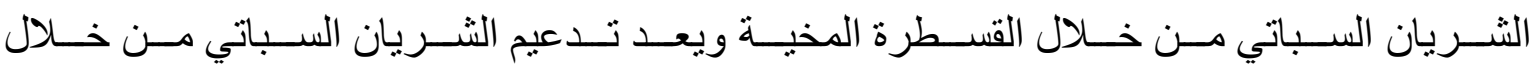

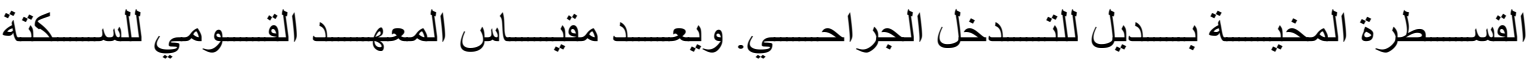
الاماغية هو أحد الوسائل المستخدمة في تقييم حالة مرضى السكتة الدماغية.

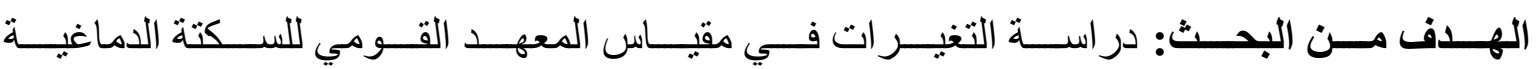
عقب تدعيم الثريان السباتي من خلال القسطرة المخية.

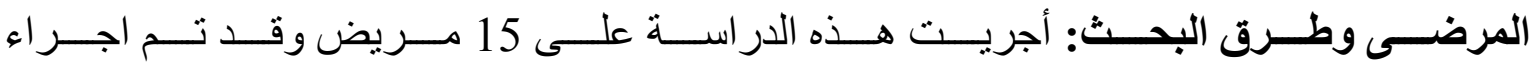

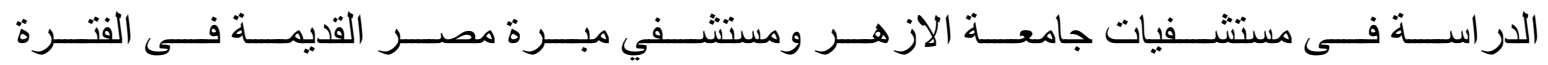

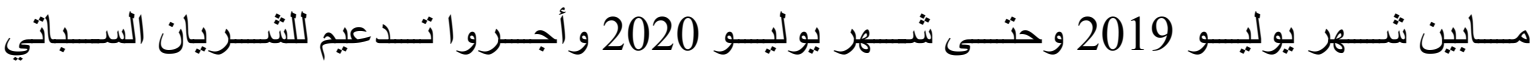

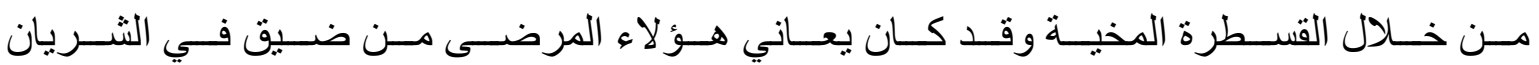
السباتي بدرجة عالية ولا توجد أعر اض (أكثر من 70\%) أو في وجود أعراض.

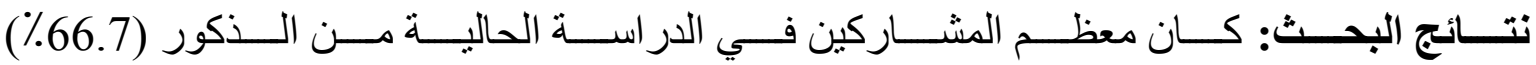

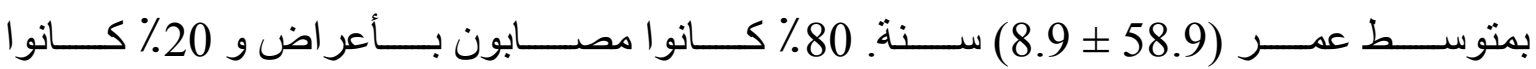

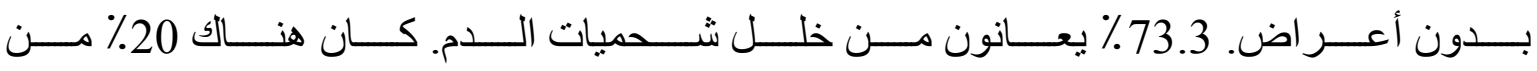

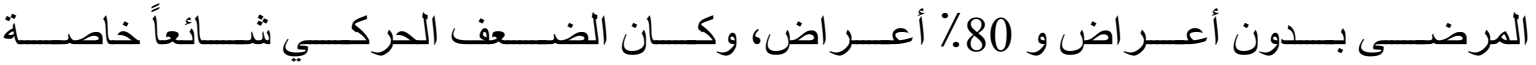

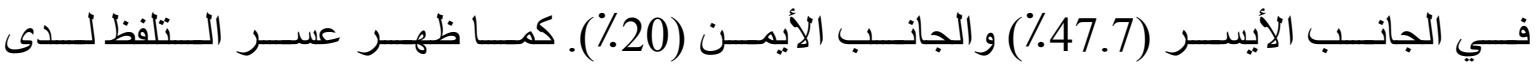

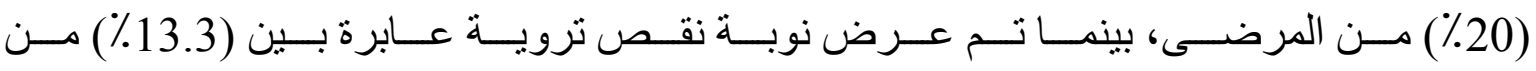

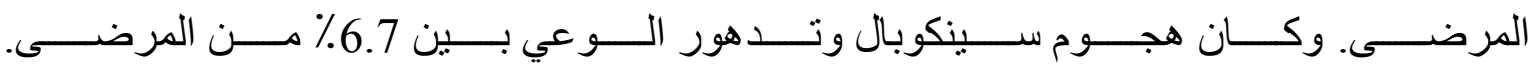

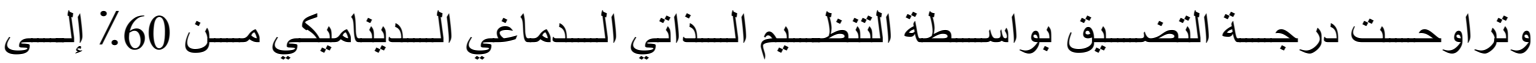

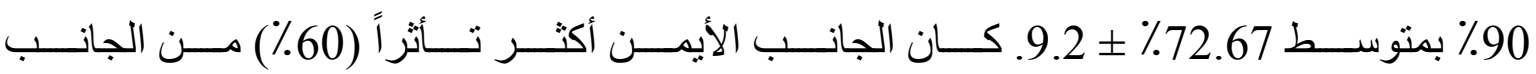




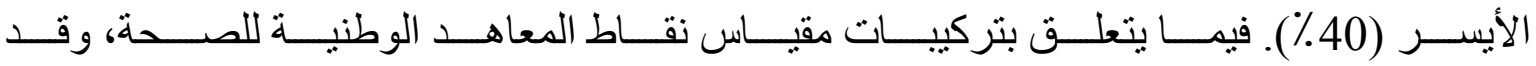

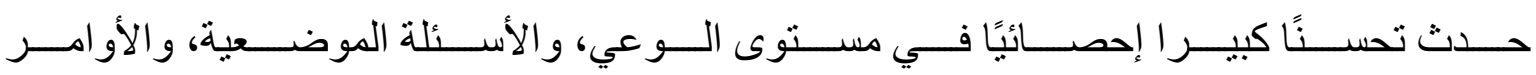

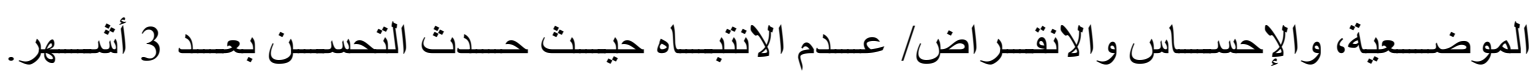

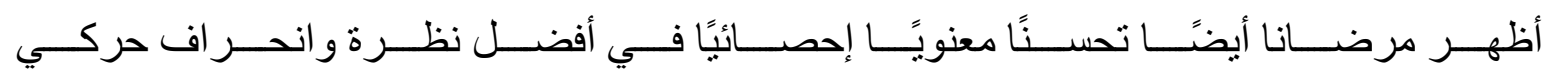

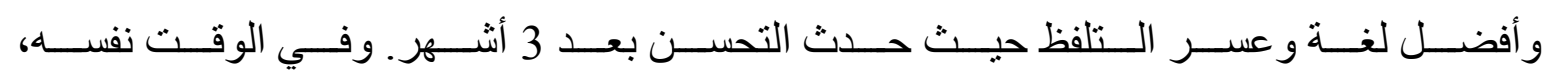

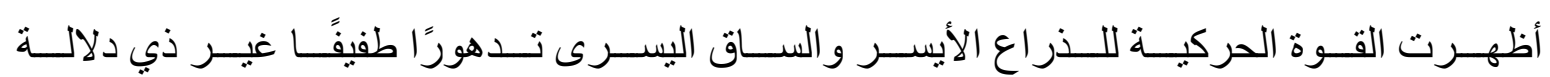

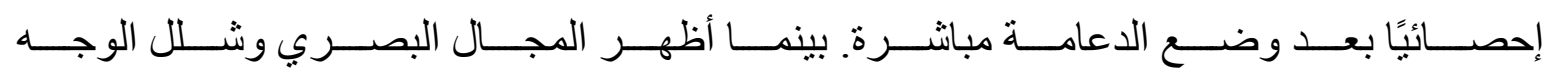
وبنى تزنح الأطر اف اختلافات طفيفة بين مرضى الدر اسة.

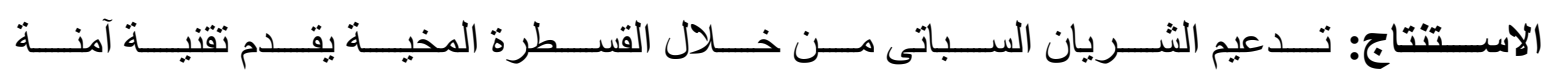
وناجحة لعلاج ضيق الثريان السباتي. 